\title{
New ANCHORS For Business Schools In The New Economy
}

Monzurul Hoque, (E-mail: m.hoque@att.net), Saint Xavier University

\begin{abstract}
In this article we illustrate changes taking place in the context, economy and environment in which business schools currently operate. These changes point out the continuous need to devise new business school models to survive and prosper. Further, we elaborate a contextual perspective obtained from the current best practices of business schools to spring forth new strategies in a changing world.
\end{abstract}

After decades of unprecedented growth, business schools are facing an outlook that is suddenly looking much less sunny. Increasing pressure to globalize, declining enrollments, criticism from corporate America, and changes in both business and society are forcing business schools to face the fact that they must adapt or die.

As the economy continues to move toward an information-based system, and corporations more heavily favor active learning over theoretical studies, business schools are facing an intensifying crisis. The schools' best hope is to systematically analyze their own strategies and integrate the concepts of the new economy with their own core values.

To devise a strategy for succeeding in these turbulent times, we suggest schools base their strategies in the ANCHORS plan. This helps school officials build from a base that identifies their missions and core competencies, leads them to organizational effectiveness, and helps them create a sustainable advantage in their marketplace. The ANCHORS plan provides a multidimensional basis for coping with changing times and also helps schools identify the markets they will serve.

\section{Change In The Context}

A contextual change in Management Education is taking place in American colleges and universities after decades of unprecedented growth. Increased globalization, declining enrollments, increased criticism from corporate America, and the need for new curricular developments in response to competition and changes in the business and society have initiated schools of business to formulate strategies for survival in the new information economy. Additionally, the public is demanding tangible proof that colleges and universities are preparing business students for a competitive and uncertain work environment. The overall effectiveness of one school of business versus another is heatedly debated in popular press along with ratings of faculty publications, graduate salaries, job offers and initial prospects, and academic accreditation. Both internal and external stakeholders suggest business schools develop leadership and human relations skills, the so called soft skills, in addition to effective problem solving skills for today's contemporary business students. Part of the problem with measuring the effectiveness of business schools lies in their dual role as academic and professional institutions serving two different constituencies, one academic and the other practice. Conceptual teaching with rigor in theory and scholarship competes with active learning from practical applications. In fact, many companies are strongly

Readers with comments or questions are encouraged to contact the author via email. 
leaning towards active learning to be effective manager, an alarming prospect for business schools in losing its cash cow (e.g.BizEd, AACSB, Sept./Oct. 2002).

With the uncertainty that faces business schools, in coming years the public debate will assume greater intensity as the economy moves into a new phase. Therefore, it becomes imperative that systematic analysis of strategic intentions of the school or department of business is conducted.

\section{Meeting The Challenge}

Given the current and prospective challenges faced by business schools compounded by the turbulent changes in the global economy, the business schools are actively engaged in devising strategies towards sustaining their competitive advantage and inventing new ones. Strategies differ from school to school reflecting the respective core competencies and values in the context of the changing time. In what follows, we illustrate a conceptual base reflecting the changing context, economy and environment for springing forth such strategies.

\subsection{A Contextual Perspective For Strategies}

We accept at the outset that the goal of a business school is to provide quality management education programs with one stop access (e.g., AACSB international and ACBSP mission statements) so that attributes of effective managers are instilled in the students. One way to achieve this goal is to formulate strategies based on the following strategic intention perspective in the light of mission and core competencies of respective business schools.

In the ANCHORS strategic intention perspective, $\mathrm{A}$ denotes access, $\mathrm{N}$ denotes novelty, $\mathrm{C}$ denotes cost, $\mathrm{H}$ denotes hybridization, $\mathrm{O}$ denotes organization, $\mathrm{R}$ denotes rapid deployment, and $\mathrm{S}$ denotes stabilization and search issues. Business school decision makers developing strategies will find the ANCHORS perspective as a useful multidimensional springboard to bring forth new strategies in the current changing times. The strategies will integrate the understanding of new economy with the core concepts and values that will support a high quality learning environment consistent with the mission and objectives of business school or program. The final outcome will identify the students it will serve, and the programs it will offer in view of its core competencies. Particularly, $\mathrm{A}$ and $\mathrm{N}$ describe the strategic intentions for current and future products and services, $\mathrm{C}$ and $\mathrm{H}$ describe strategic intentions for cost, $\mathrm{O}$ is the master key that describes strategic intention for value; $\mathrm{R}$ and $\mathrm{S}$ describe strategic intentions for dynamism in terms of nimbleness and flexibility in the face of opportunities and threats.

\subsection{New Economy Some Stylized Facts ${ }^{1}$}

The nature of Internet use is changing rapidly, and the need for Internet access is exploding. Add to that new technologies that enable individuals and businesses to get up and running on the Internet and the possibilities are endless. Access to networks, or connectivity, is just one piece of the puzzle for societies entering this new era. More fundamentally, this transition requires major shifts in the regulatory environment, and renewed attention to public-private partnerships and to social services. In short, the emergence of the "new economy" affects everything.

Characteristics of New Economy: The advent of the new economy was first noticed as far back as 1969, when Peter Drucker perceived the arrival of knowledge workers. The new economy is often referred to as the Information Economy, because of information's superior role (rather than material resources or capital) in creating wealth. The new economy is largely characterized by:

- Deregulated environment, especially, telecommunication (1996) and financial industry (1998) here and abroad.

\footnotetext{
${ }^{1}$ See Greenspan's lecture on new economy at various times in 2001.
} 
- $\quad$ Economy characterizes a chaotic structure. Sensitive dependence on initial condition exhibited by paradigm shifting non-linear outcome. Everything is related to everything else.

- $\quad$ Connecting all to all. Metcalf's law (more gives more) - value comes from abundance not scarcity.

- $\quad$ One to many outcomes. Sharp contrast with industrial economy (one to one correspondence); no limits to growth (silicon used to be used for glass and now chip and someday some think more valuable. There will be risk of job loss (involuntary migration) and risk of people loss (voluntary migration- CEO of General Electric on 60 minutes on Oct. 29, 2000 saying the bottom $10 \%$ will be more productive elsewhere). Employer and employee loyalty will shift from organization to network.

- Law of increasing returns. Change and growth in real terms correspond to risk and return in financial terms.

- $\quad$ Law of decreasing price (Moore's law) precursor of Law of creative destruction.

- $\quad$ Law of churn (effective churning is an art).

- $\quad$ Law of inefficiencies (seizing the opportunity rather than optimize the existing) Don't solve problems, seek opportunities. Similar to Herbert Simon's idea of satisficing instead of maximizing.

For the old economy, researchers have developed a number of multidimensional measures of effectiveness to describe the process by which decision makers determine the overall performance of the organization to its external and internal environments under the old economy (Cameron, 1978; Peters \& Waterman, 1982; Quinn \& Rohrbaugh, 1983). Cameron's (1978) construct of organizational effectiveness is a theoretical framework that incorporates the use of multiple perspectives that can be recorded in relationship to one another. The task in this paper is to develop a multidimensional measure of business education effectiveness that will enable the School to do the right thing under the new economy.

However, establishing right measurements of effectiveness for schools of business in general is of little use if it does not address the issues that will diagnose and assess the wrong ones. In below we derive a multidimensional measure of business school effectiveness including external and internal factors that will significantly impact organizational effectiveness and failure avoidance.

\section{The ANCHORS Model}

In this section a new one stop access business education model that will maximize a business school's success in the new world economy. The model is found by asking following two questions.

- What need to be absolutely right for business programs to succeed by taking advantage of changes in the technology and economy?

- What can go wrong other than inhibitors of success that can lead to uncontained failure?

At the outset we accept that the goal of a Business School is to provide quality of management education programs with one stop access (see, e.g., AACSB and ACBSP mission statements). To achieve this goal we present the following business school model as a possible answer.

Goal: Provisioning of Quality Management Education with One Stop Access.

Objective: Maximize quality management education access revenue to cost ratio (EBITDA in financial terms), s.t. 'ANCHORS': 
$\begin{array}{ll}\text { - } & \text { Access } \\ \text { - } & \text { Novelty } \\ \text { - } & \text { Hybridization } \\ \text { - } & \text { Organization } \\ \text { - } & \text { Rapid Deployment } \\ \text { - } & \text { Stabilization and search }\end{array}$

The decision makers maximize quality management education access to cost ratio subject to "ANCHORS" strategy. A and $\mathrm{N}$ define current and future products; $\mathrm{C}$ and $\mathrm{H}$ define cost, $\mathrm{O}$ is the master key that defines the value; $\mathrm{R}$ and $\mathrm{S}$ define dynamism in terms of nimbleness and flexibility in the face of opportunities and threats. Let us now detail the perspectives and illustrate some popular strategies reflecting the perspectives.

\subsection{Access Perspective:}

The first strategic intention is to maximize access to knowledge services (teaching, learning, and leading) for the targeted segments. The intention is to provide one stop access to faculty and content developed by school's dynamic faculty using connectivity for delivery on campus, on-line, on cohort premises, among others. Differentiated product with totally commoditized services is provided as changes in knowledge media and economy will dictate life long learning rather than the traditional strict age based system. Quality is assured in terms of technical, economical (value) and managerial aspects (support).

Popular Strategy:

A recent example of a strategy adopted by some business schools reflecting this intention is to provide students access to knowledge services (teaching, learning, leading) by relying on a blending of classroom technology and distance education resources for connectivity, and school's dynamic faculty for content. The program is currently differentiated by time (accelerated, traditional format), nature of credential (degree, certificate etc.), and by credit and non-credit option offered under total commoditized services. The university's established strengths in scientific and technological entrepreneurship, interdisciplinary inquiry, and interactive learning is used to provide access to program convergence.

\subsection{Novelty Perspective:}

This is where future leadership in provisioning will make its mark. The intention is to set in the gale of creative destruction to sort out the exit management programs and usher in the new ones. In the October 2002 Business Week biennial ranking, the dean of the number one ranked business school has this thing to say about novelty - "We"ve got a pro-active culture of change and innovation - and we practice what we preach."

Popular Strategy:

A common strategy reflecting this intent to ensure novelty in content, business schools enlist a small group of special adjunct faculty who has particular expertise in one or more relevant aspects of business or business practice. Further, university's entrepreneurship and incubator programs and technology are leveraged to create and build entrepreneurial and innovative programs. This will reduce the failure to obtain first mover's advantage.

\subsection{Cost Perspective:}

The intention is to achieve cost leadership in provisioning differentiated product to targeted segments by minimizing integrated cost. Probability of failure to prevent bad outcome/s (failure avoidance) is minimized. Integrated cost reflects the cost of success factors and cost of failure avoidance. Thus, the costs of successful programs and cost of failure avoidance for both current and novel programs are minimized. 
Popular Strategy:

Capital campaigns, emphasis on development of alumni relationship and on technology are some of the recent time-honored strategies followed by business schools to incorporate this intention. These reduce internal costs by being sources of fund for programs on the one hand and preventing bad outcomes on the other. Alumni networking also help keep the job placement rate high, thereby avoiding the failure of uncontained nature. Small change can have significant impact despite curricular strength. The technology of the school is the fertile ground in which cost leadership and product differentiation bloom.

\subsection{Hybridization Perspective:}

The intention is to accept the coexistence of different provisioning systems. Connecting students to content through a portfolio of delivery modes maximizes hybridization. This is more than diversification. This will lead to higher access revenue to cost ratio in two ways. First, cost is reduced through diversification gain. Second, hybridization will also maximize the access thereby increasing revenue. Thus, hybridization is a productive approach to attain growth, and maintaining leadership at the same time. The convergence of knowledge media like classroom delivery, on-line delivery and the likes will increasingly take place due to convergence of computer and telecommunications promoted by the new economy.

Popular Strategy:

Many business schools have started to use classroom technology and distance education to help secure hybridization in connectivity and delivery of knowledge services can be a strategy to reflect this intention. Yet others seek out partnerships to achieve common goal with new relationship management structure.

\subsection{Organization Perspective ${ }^{23}$ :}

It is the key link between history and mystery - between discovering opportunity and making it happen. Innovation and flexibility are two fundamental drivers of value. Intent is to have an organization that does not stifle internal or external innovating efforts. Such a small change in intention leads to a dramatic shift. If not done properly leads to uncontained failure. The recent shake up in business school ranking illustrates this fact.

Popular Strategy:

This is a different mindset from the industrial era paradigm where small cause had small consequence. Information economy is changing the nature of sustainable organizations. Hierarchical or command and control organizations will not work in such an environment. As the information is moved through the system due to enormous capacity created by technology, it will challenge and gradually disembody the organization. The recent case in point is the uncontained failure of Enron. The Enron employees could not assert their values in time because of fear of consequences under command and control leadership. A collaborative leadership style makes the problem visible early, and avoids the failure.

The flexibility is the other driver of value in an organization. This creates the capacity to change and evolve in the face of complex and evolving world. The new structure emerges out of the old which no longer can

\footnotetext{
${ }^{2}$ Internal structure...that's the organization... and includes assets like patents and brand names, manuals, systems processes...everything that constitutes what we normally call "organization", including very fuzzy areas called culture. We regard managers as part of internal structure because it's their task to maintain and keep it viable over the long run, thereby ensuring the viability of the organization.

${ }^{3}$ A key internal factor found in research to influence effectiveness is organizational culture. The importance of understanding culture lies in the fact that core values and assumptions are often at the root of organizational structures in determining organizational development (Denison \& Spreitzer, 1991). Culture in organizations can be explained as "a set of symbols, ceremonies, and myths that communicate the underlying values and beliefs of that organization to its employees"(Ouchi, 1981). Research by Ouchi (1980, 1981, 1983) suggested three types of organizational culture: 1) Clans- Socialization of all organizational members to a common goal. 2) Markets- Measuring contributions of organizational members to the common good and 3) Hierarchies- Contractual specifications of rights and duties to organizational members.
} 
promote the progress rather impedes it. Thus, organization is a living organism that springs forth newness and breed on its own, provided a capacity is created. The new science of chaos points out that this capacity for creating enormous change can be obtained by a simple congruence or agreement at the heart of the organization. A strategy that can implement this intent of flexibility can be found in a management wisdom that states that "in essentials there should be agreement, in non essentials freedom and in all things charity." This age-old management wisdom is from St. Augustine. The mission statement of business schools can be worked to reflect this intent, if not there. A point can be noted that the majority of CEOs come from business schools where collective efforts are emphasized to solve problems in the courses. More often, these students who work well in groups, become corporate leaders with strong integrity.

\subsection{Rapid Deployment Perspective:}

Rapid deployment for firsts' profit once the opportunities are identified will be a crucial intent expressed in formal strategy. The windows of opportunity have the habit of slamming shut if one waits for full market validation. This is a demonstration of nimbleness. The fast and nimble response to the needs of students/stakeholders will achieve higher rating among students. Also, this will enable the students to rake in higher return. Rapid deployment catches the product at its pioneering and expansion stages with high attendant profit for students. Such an emphasis can help simplify work systems and processes.

Popular Strategy:

A proactive and quick acting strategy reflecting this intention finds its expression in specialized programs. Some business schools already assumed leadership advantage in Leadership, Information Age and Financial Engineering programs and raking in first mover's advantage. A study by the AACSB International in summer 2001 show that the specialized degree programs constitute $30 \%$ of all Masters enrollments in business schools.

\subsection{Stabilization and Searching Perspective:}

This takes back to the top of the cycle to maintain the course of leadership through hold, buy, partnering/peering or sell avenues. Schools must act first to stop the bleeding, and then get themselves in shape for the future. Market evolution and devolution are essential disruptive changes that bring high return with them, and schools must be prepared to follow those changes by terminating moribund programs and providing new ones.

Popular Strategy:

"Build it, optimize it, and they will come" - can not be the strategy in the ANCHORS perspective. One strategy reflecting this intent is to stabilize the programs through program review and curricular assessment, and then search for innovative new approaches that integrate current technology and still maintain a "high-touch" level of interaction with students. Effective churning is an art of survival, and learning how to churn successfully should be the part of the strategy. That is what some schools expect from its students as well, when they say, "over and above a traditional management degree, school graduates are equipped to change the world by way of their combined focus on management and technology."

\section{Implement Or Procrastinate}

From the above we realize that the ANCHORS plan is an empirical based model. What is involved is to realize that effective churning is an art. Let's look at the Table 1 for details.

The ANCHORS business education model will maximize success by doing what needs to be right but at the same time minimize the failure to seize the emerging possibilities. This is both the art and science of management education. 
Table 1: Effective Churning Is An Art

\begin{tabular}{|c|c|c|}
\hline Art of Decision Making & \multicolumn{2}{|c|}{$\begin{array}{l}\mathrm{H}_{0} \text { : Related Curriculum's promise is not significantly different from zero } \\
\mathrm{H}_{\mathrm{A}} \text { : Related Curriculum's promise is significant }\end{array}$} \\
\hline Organizational Decision & $\mathrm{H}_{0}$ is True & $\mathrm{H}_{0}$ is False \\
\hline $\begin{array}{l}\text { No Action or Wait and See } \\
\text { Approach }\left(\text { Accept } \mathrm{H}_{0}\right)\end{array}$ & Good Decision & $\begin{array}{l}\text { TRAP II } \\
\text { Power of Decision Making is to minimize: } \\
\text { Hazard of exclusion due to adverse under } \\
\text { uncertainty and subsequent random exit } \\
\text { ( Beta or Type II error) }\end{array}$ \\
\hline Proactive Engagement $\left(\right.$ Reject $\left.\mathrm{H}_{0}\right)$ & $\begin{array}{l}\text { TRAP I } \\
\text { Precision of decision Making is to } \\
\text { minimize: } \\
\text { Hazard of early entry due to adverse } \\
\text { decision under uncertainty hurting } \\
\text { core competencies leading to random } \\
\text { exit (alpha or Type I error). }\end{array}$ & $\begin{array}{l}\text { Fast Mover's Advantage. Probability of } \\
\text { competitive exit due to subsequent fall in } \\
\text { prices considerably lower. }\end{array}$ \\
\hline
\end{tabular}

By anchoring the strategies in basic ANCHORS perspective, schools can devise concrete and integrated strategies that will lead them to success as they take advantage of new possibilities. Their strategies will then reflect changes taking place in the context, economy and environment in which business schools currently operate.

\section{Concluding Remarks}

In above an effort is made to illustrate that in the new economy a Business School needs to revamp its old business model in order to succeed. The nature of new economy is radically different from the old and hence, adjusting or fine-tuning the old model will not simply work. A new business model in the light of new economy and new management education industry has been developed here which a Business School can successfully adopt for institutional effectiveness. To devise a strategy for succeeding in these turbulent times, we suggest schools base their strategies in the ANCHORS plan. This helps school officials build from a base that identifies their missions and core competencies, leads them to organizational effectiveness, and helps them create a sustainable advantage in their marketplace. The ANCHORS plan provides a multidimensional basis for coping with changing times and also helps schools identify the markets they will serve.

\section{References}

1. AACSB, 2002. BizEd, St. Louis

2. AACSB. 2001. Standards and Criteria. St. Louis.

3. Cameron K.S. 1978. "Measuring Organizational Effectiveness in Institutions of Higher Education." Administrative Science Quarterly, 23:604-632.

4. Chistensen, C.M. 1997. The Innovator's Dilemma. (Boston: Harvard Business School Press).

5. Courtney, H., J. Kirkland, and P.Viguerie. 1995. “ Strategy under Uncertainty." Harvard Business Review, vol. 73 (January/February), pp. 43-53.

6. Day,G.S. and D.B. Montgomery. 1983. “ Diagnosing the Experience Curve.” Journal of Marketing, vol. 47, no. 3 (1983).

7. Denison, D.R. and Spreitzer,G.M. 1991. "Organizational culture and organizational development." Research in organizational change and development, 5: 1-21. JAI Press Inc.

8. Dosi, G. 1983. "Technological Paradigms and Technological Trajectories," Research Policy, vol. 11, pp. 147-62.

9. $\quad$ Drucker. P.F. 1994. "The Theory of Business," Harvard Business Review, vol. 72, no. 5, pp. 95-104.

10. Greenspan, A. 2001. "The New Economy." Lecture in the Silicon Valley Club.

11. Kahneman, D. and A. Tversky. “Prospect Theory.” Econometrica, vol. 47 (1979), pp. 283-291. 
12. Kahneman D., J. L. Knetsch, and R. Thaler. 1990. “Experimental Tests of the Endowment Effect and the Coase Theorem." Journal of Political Economy, vol. 98, no. 61 (December), pp. 1325-1348.

13. Ouchi, W.G. 1980. "Markets, bureaucracies, and clans." Administrative Science Quarterly, 25:129-141 . 1981. Theory Z: How American Business Can Meet the Japanese Challenge. Reading Ma., Addison-Wesley.

14. Ouchi, W. \& Wilkins, A. 1985. “Organizational culture.” Annual Review of Sociology, 1:457-483.

15. Tushman, M. and P. Anderson. 1986. "Technological Discontinuities and Organizational Environment." Administrative Science Quarterly, vol. 31 (1986), pp. 439-456.

16. Williamson, P. 1999. "Strategy as Options on the Future." Sloan Management Review, vol. 40, no. 3 (spring).

17. Yoffie, D.B. 1996. "Competing in the Age of Digital Convergence." California Management Review, vol. 38 (summer).

Notes 